CLINICAL STUDY

\title{
Testosterone supplementation in healthy older men drives GH and IGF-I secretion without potentiating peptidyl secretagogue efficacy
}

\author{
Johannes D Veldhuis, Daniel M Keenan ${ }^{1}$, Kristi Mielke, John M Miles and Cyril Y Bowers ${ }^{2}$ \\ Division of Endocrinology and Metabolism, Department of Internal Medicine, Mayo Medical and Graduate Schools of Medicine, General Clinical Research \\ Center, Mayo Clinic, Rochester, MN 55905, USA, ${ }^{1}$ Department of Statistics, University of Virginia, Charlottesville, VA 22908, USA and ${ }^{2}$ Department of \\ Medicine, Tulane University Health Sciences Center, New Orleans, LA 70112, USA
}

(Correspondence should be addressed to J D Veldhius; Email: veldhuis.johannes@mayo.edu)

\begin{abstract}
Objective: Testosterone supplementation increases GH and IGF-I concentrations in healthy older men via unknown mechanisms. We examine the hypotheses that (i) testosterone amplifies stimulation of GH secretion by GH-releasing peptide (GHRP)-2 or GH-releasing hormone (GHRH) infused with L-arginine to limit somatostatin outflow (i.e. upregulates each agonistic pathway), (ii) testosterone augments the effect of both peptidyl secretagogues infused together (i.e. reduces opposition by hypothalamic somatostatin) and (iii) abdominal visceral fat (AVF) mass is a negative determinant of specific secretagogue-stimulated GH secretion.

Design: Randomized double-blind crossover design of placebo versus testosterone administration in healthy older men.

Methods: Deconvolution analysis was used to estimate basal GH secretion and the mass (integral) and waveform (time-shape) of GH secretory bursts.

Results: Statistical contrasts revealed that administration of testosterone compared with placebo in seven men aged 60-77 years increased fasting concentrations of GH $(P<0.01)$ and IGF-I $(P=0.003)$, and basal $(P<0.005)$ and pulsatile $(P<0.01) \mathrm{GH}$ secretion. Testosterone did not alter the absolute value or rank order of secretagogue efficacy: L-arginine/GHRP-2 (23-fold effect over saline $)=\mathrm{GHRH} / \mathrm{GHRP}-2$ (20-fold) $>$ L-arginine/GHRH $(7.5$-fold $)$. Waveform reconstruction indicated that each stimulus pair accelerated initial GH secretion within a burst $(P<0.01)$. Regression analysis disclosed a significant inverse association between GH secretory-burst mass and computer tomography-estimated AVF following stimulation with L-arginine/GHRH after testosterone supplementation $\left(R^{2}=0.54, P=0.015\right)$.

Conclusion: Supraphysiological testosterone concentrations augment GH and IGF-I production in the elderly male without altering maximal somatotrope responses to single and combined GHRH and GHRP-2 drive, thus predicting multifactorial mechanisms of testosterone upregulation.
\end{abstract}

European Journal of Endocrinology 153 577-586

\section{Introduction}

Growth hormone (GH) and testosterone concentrations rise together in pubertal individuals and fall in parallel in hypogonadal and older men (1-5). Administration of testosterone stimulates pulsatile and total GH production in boys with constitutional delay of puberty or isolated gonadotropin-releasing hormone (GnRH) deficiency, adults with testicular failure, female-to-male transsexual patients and elderly men with aging-related hypoandrogenemia (5-11). In contrast, testosterone supplementation in eugonadal young men does not increase GH secretion further $(5,12)$.
The hypothalmo-pituitary mechanisms by which testosterone promotes GH secretion and thereby elevates insulin-like growth factor I (IGF-I) concentrations in the human are unknown. However, in animal models pulsatile GH secretion is controlled jointly via feedforward by GH-releasing hormone (GHRH) and ghrelin (a GH-releasing peptide, GHRP), and feedback by somatostatin $(13-17)$. How testosterone regulates interactions among these principal peptidyl regulators in the human remains unclear. One consistent finding is that supplementation with testosterone before puberty as well as normal puberty in boys potentiates GHRP's stimulation of GH secretion by approximately twofold (18-20). 
The present investigation evaluates the hypothesis that testosterone supplementation in older men stimulates pulsatile $\mathrm{GH}$ secretion in part by augmenting feedforward (stimulation) by GHRH and GHRP-2 (a synthetic analog of ghrelin), and relieves feedback by endogenous somatostatin. To this end, maximally stimulatory doses of GHRH and GHRP-2 were administered individually and together following randomly ordered supplementation with placebo or testosterone $(21,22)$. To limit interpretative confounding, L-arginine was infused immediately before stimulation with an individual secretagogue, given that L-arginine putatively inhibits hypothalamic somatostatin secretion (22-25). In addition, GHRH and GHRP-2 were delivered continuously in combination, inasmuch as a reduction in somatostatin outflow would be expected to enhance stimulation by the combined secretagogues. A high-precision robotics chemiluminescence GH assay and a new deconvolution methodology were applied to reconstruct both the mass and waveform (shape) of single and dual peptide-stimulated GH secretory bursts after placebo and testosterone supplementation $(26-28)$.

\section{Methods}

\section{Subjects}

Participants provided voluntary written informed consent approved by the Mayo Institutional Review Board. The protocol was reviewed by the US Food and Drug Administration under an investigator-initiated new drug number. Exclusion criteria were recent transmeridian travel (within 2 weeks), night-shift work, significant weight change ( $\geq 3 \mathrm{~kg}$ in 1 month), acute or chronic illness, psychiatric treatment or substance abuse. Volunteers were nonsmokers and free of known or suspected cardiac, cerebral or peripheral arterial or venous thromboembolic disease. None was receiving neuroactive medications. Some enrollees continued to take multivitamins, ferrous sulfate, calcium carbonate, aspirin and ibuprofen on nonstudy days. Each subject had an unremarkable medical history and physical examination, and normal screening laboratory tests of hepatic, renal, endocrine, metabolic and hematologic function.

The mean \pm S.E.M. age was $66 \pm 2.2$ years (range 60-77 years) and mean body mass index was $26 \pm 1.3 \mathrm{~kg} / \mathrm{m}^{2}$ (range $22-29 \mathrm{~kg} / \mathrm{m}^{2}$ ). Inclusion criteria were concentrations of follicle-stimulating hormone (FSH) of 2-15 IU/l, luteinizing hormone (LH) of $2-10 \mathrm{IU} / \mathrm{l}$ and total testosterone of $>300 \mathrm{ng} / \mathrm{dl}$ (10.5 nM).

\section{Statistical design}

The study design was a prospectively randomized, placebo-controlled, double-blind within-subject crossover intervention. Each volunteer received three consecutive weekly i.m. injections of placebo (saline) and testosterone enanthate $(200 \mathrm{mg})$ in separate, randomized order. 6 weeks was the minimal washout interval. Thus injections occurred on days 1,8 and 15. The foregoing androgen-supplementation schedule was chosen because it is known to double 24-h GH secretion and elevate IGF-I concentrations by $>30 \%$ in older but not younger men (5). The precise thresholds for these testosterone effects in the older male are not known. Secretagogue infusions were scheduled within the post-intervention time window, days 17-21 inclusive (day 1 was defined as the day of the first saline or testosterone injection).

\section{Sampling paradigm}

Volunteers were admitted to the General Clinical Research Center, Mayo Clinic, Rochester, MN, USA, on the evening before study to allow overnight adaptation to the unit. To obviate food-related confounds, subjects were given a constant meal (turkey sandwich or vegetarian alternative) of $500 \mathrm{kcal}$ containing $50 \%$ carbohydrate, $20 \%$ protein and $30 \%$ fat at $2000 \mathrm{~h}$. Participants then remained fasting overnight until $1300 \mathrm{~h}$ the next day. To allow combined blood sampling and peptide infusion, i.v. catheters were inserted in contralateral forearm veins at $0700 \mathrm{~h}$. Blood $(8 \mathrm{ml})$ was withdrawn for later assay of baseline hormone concentrations. Samples $(1.5 \mathrm{ml})$ were collected in chilled plastic tubes containing EDTA every $10 \mathrm{~min}$ for $5 \mathrm{~h}$ between 0800 and $1300 \mathrm{~h}$ for $\mathrm{GH}$ measurements. Plasma was separated on ice and frozen at $-70^{\circ} \mathrm{C}$ within $30 \mathrm{~min}$.

\section{Infusions}

Infusions were performed on separate mornings fasting. The four protocols comprised i.v. delivery of (i) saline $(0800-1300 \mathrm{~h})$, (ii) L-arginine, $30 \mathrm{~g}$ over $30 \mathrm{~min}$ $(0930-1000 \mathrm{~h})$, followed immediately by bolus GHRH ( $1 \mu \mathrm{g} / \mathrm{kg}$; GRF; Serono, Norwalk, MA, USA), (iii) L-arginine as above followed by bolus GHRP-2 $(3 \mu \mathrm{g} / \mathrm{kg})$ and (iv) combined GHRH and GHRP-2 at a constant rate of $1 \mu \mathrm{g} / \mathrm{kg}$ per h each (0800-1100 h). The foregoing peptide doses are maximally stimulatory in dose-response analyses in postmenopausal women $(21,22)$. The order of infusions was randomized in each subject.

\section{Hormone assays}

Plasma GH concentrations were measured in duplicate by automated, ultrasensitive, double-monoclonal imm unoenzymatic, magnetic particle-capture chemiluminescence assay using $22 \mathrm{kDa}$ recombinant human $\mathrm{GH}$ as the assay standard (Sanofi Diagnostics Pasteur Access, Chaska, MN, USA). All samples $(n=248)$ from any given subject were analyzed together. 
Sensitivity was $0.010 \mu \mathrm{g} / \mathrm{l}$ (defined as three standard deviations above the zero-dose tube). Median intraand interassay coefficients of variation (CVs) were 5.2 and $6.3 \%$, respectively, at the $\mathrm{GH}$ concentrations measured here. No values fell below $0.020 \mu \mathrm{g} / \mathrm{l}$. Cross-reactivity with $20 \mathrm{kDa}$ GH was $<5 \%$. Serum concentrations of testosterone, LH and FSH were quantitated by automated chemiluminescence assay (ACS 180; Bayer, Norwood, MA, USA), using as LH and FSH standards the First and Second International Reference Preparations, respectively (29). Procedural sensitivities for testosterone, LH and FSH are $0.7 \mathrm{nM}$ and 0.2 and $0.4 \mathrm{IU} / \mathrm{l}$; intraassay CVs were 5.4, 6.3 and $7.4 \%$, and interassay CVs were $7.3,6.5$ and $8.5 \%$, respectively. Estradiol was quantitated in batches by RIA with a sensitivity of $37 \mathrm{pM}$ and within-assay CV of $6.7 \%$ (29). SHBG was assayed by IRMA (4). Total IGF-I concentrations were measured by RIA after acid-ethanol extraction (Nichols Institute Diagnostics, San Clemente, CA, USA) with mean intra- and interassay CVs of 5.3 and $6.2 \%$, respectively (30).

\section{Visceral fat mass}

Intra-abdominal visceral fat mass was estimated by single-slice, abdominal computed tomography (CT) scan at L5, exactly as described in (31).

\section{Deconvolution analyses of basal (nonpulsatile) and GHRH-stimulated burst-like GH secretion}

Earlier deconvolution methods may yield nonunique estimates of basal secretion, secretory-burst mass, pulse number and hormone-elimination rates (32). To address this technical issue, basal and pulsatile $\mathrm{GH}$ secretion were estimated simultaneously by way of a new maximum-likelihood-based, variable-waveform model statistically conditioned on biexponential kinetics and estimated pulse times, as recently validated mathematically and experimentally $(26,27,33)$. Thereby, we determine the impact of testosterone and placebo on saline- and GHRH- and/or GHRP-2-stimulated GH secretory-burst mass and waveform. The analytical strategy was illustrated clinically in $(34,35)$.

\section{Variable-waveform deconvolution analysis}

From a statistical perspective, there are four interventional assignments involving both placebo and testosterone supplementation. The four infusion types are here denoted as $k=1,2,3,4$. Each subject, $j=1,2, \ldots$, was sampled every $10 \mathrm{~min}$ for $5 \mathrm{~h}$. At a given time, $t$, the GH-secretion rate (unobserved) and $\mathrm{GH}$ concentration (measured) in subject $j$ for condition $k$ are designated by $Z_{j}^{(\mathrm{k})}(t)$ and $X_{j}^{(\mathrm{k})}(t)$, respectively. Concomitant basal GH secretion is given by $\gamma^{(\mathrm{k})}$. Burst-like hormone secretion before and following secretagogue injection at time $T$ is described by two terms: (i) the waveform or instantaneous (unit-area-normalized) rate of $\mathrm{GH}$ secretion over time, $\psi(\cdot)$ and (ii) the mass of $\mathrm{GH}$ released per unit distribution volume in the burst $(\mu \mathrm{g} / \mathrm{l}), M(26,27)$. The waveform function (burst shape) is defined by the generalized Gamma probability density:

$$
\psi^{(\mathrm{k})}(s) \propto s^{\left(\beta_{1}^{(\mathrm{k})} \beta_{3}^{(\mathrm{k})}-1\right)} e^{-\left(s / \beta_{2}^{(\mathrm{k})}\right)^{\beta_{3}^{(k)}}}, s \geq 0, k=1,2,3,4
$$

The three $\beta$ parameters of the $\psi$ function permit variable asymmetry or approximate Gaussian-like symmetry of secretory-burst shape (33).

The present analytical formulation is distinctive by way of reconstructing (i) a common waveform function for the placebo and another for the testosterone intervention, one in each of the four interventions, $k$, and (ii) a mean amount of GH secreted after each saline/ secretagogue intervention, $M^{(\mathrm{k})}$. The mass secreted in any given subject is then $M^{(\mathrm{k})}$ plus a random variation, $A_{\mathrm{j}}^{(\mathrm{k})}$. The total (basal and pulsatile) GH-secretion rate $(\mu \mathrm{g} / \mathrm{l}$ per $\min )$ in subject $j$ under condition $k$ is:

$$
Z_{\mathrm{j}}^{(\mathrm{k})}(t)=\gamma^{(\mathrm{k})}+\left(M^{(\mathrm{k})}+A_{\mathrm{j}}^{(\mathrm{k})}\right) \psi^{(\mathrm{k})}(t-T), \quad t \geq 0
$$

and the predicted GH concentration is:

$$
\begin{aligned}
X_{\mathrm{j}}^{(\mathrm{k})}(t) & =\left(a e^{-\alpha_{1} \mathrm{t}}+(1-a) e^{-\alpha_{2} \mathrm{t}}\right) X_{\mathrm{j}}^{(\mathrm{k})}(0) \\
& +\int_{0}^{t}\left(a e^{-\alpha_{1} \mathrm{t}}+(1-a) e^{-\alpha_{2} \mathrm{t}}\right) Z_{\mathrm{j}}^{(\mathrm{k})}(r) d r \\
& \approx \gamma^{(\mathrm{k})} \times\left(\left(a / \alpha_{1}\right)\left(1-e^{-\alpha_{1} \mathrm{t}}\right)+\left(1-a / \alpha_{2}\right)\left(1-e^{-\alpha_{2} \mathrm{t}}\right)\right) \\
& \int_{0}^{t}\left(a e^{-\alpha_{1}(\mathrm{t}-\mathrm{r})}+(1-a) e^{-\alpha_{2}(\mathrm{t}-\mathrm{r})}\right) \\
& \times\left(M^{(\mathrm{k})}+A_{\mathrm{j}}^{(\mathrm{k})}\right) \psi^{(\mathrm{k})}(r-T) d r
\end{aligned}
$$

or basal secretion plus pulsatile secretion, where $a$ is the proportion of rapid to total elimination, $\alpha_{1}$ and $\alpha_{2}$ are rate constants of rapid and slow elimination, and $X(0)$ is the starting hormone concentration (27). Here, $\alpha_{1}$ is fixed at the shortest half-life estimable for $10 \mathrm{~min}$ of sampling, $6.93 \mathrm{~min}$, and $\alpha_{2}$ at the reported value of $20.8 \mathrm{~min}$ for endogenous GH (52).

The model is represented fully by the set of parameters defined by $\theta^{(\mathrm{k})}$ for $k=1,2,3,4$ :

$$
\theta^{(\mathrm{k})}=\left(\beta_{1}^{(\mathrm{k})}, \beta_{2}^{(\mathrm{k})}, \beta_{3}^{(\mathrm{k})}, \gamma^{(\mathrm{k})}, M^{(\mathrm{k})}, \sigma_{\mathrm{A}}^{(\mathrm{k})}, \sigma_{\varepsilon}^{(\mathrm{k})}\right.
$$

Measured GH concentrations, $Y_{\mathrm{j}, \mathrm{i}}^{(\mathrm{k})}$, are considered a discrete time sampling (indexed by $i$ of $n$ data points) of the foregoing continuous processes, as distorted by observational error, $\varepsilon_{\mathrm{i}}$ :

$$
Y_{\mathrm{j}, \mathrm{i}}^{(\mathrm{k})}=X_{\mathrm{j}}^{(\mathrm{k})}\left(t_{\mathrm{i}}\right)+\varepsilon_{\mathrm{i}}, \quad i=1, \ldots, n .
$$


The discretized secretion rate, $Z_{\mathrm{j}, \mathrm{i}}^{(\mathrm{k})}=Z_{\mathrm{j}}^{(\mathrm{k})}\left(t_{\mathrm{i}}\right), i=1, \ldots, n$, is reconstructed as the conditional expectation evaluated at the maximum likelihood estimate, $\hat{\theta}^{(\mathrm{k})}$ :

$$
\begin{aligned}
& \hat{Z}_{\mathrm{j}, \mathrm{i}}^{(\mathrm{k})}(i=1, \ldots, n) \\
& =E_{\theta^{(\mathrm{k})}}\left[Z_{\mathrm{j}, \mathrm{i}}^{(\mathrm{k})}, i=1, \ldots, n \mid Y_{\mathrm{j}, \mathrm{i}}^{(\mathrm{k})}, i=1, \ldots, n\right]
\end{aligned}
$$

The solution involves statistical estimation of individual subject random effects contributing to GH secretoryburst mass:

$$
E_{\theta^{(\mathrm{k})}}\left[A_{\mathrm{j}}^{(\mathrm{k})} \mid Y_{\mathrm{j}, \mathrm{i}}^{(\mathrm{k})}, i=1, \ldots, n\right]
$$

assuming that the former and observational errors are independently identically distributed and uncorrelated random Gaussian variables. In contrast, for a given subject, $j$, and intervention, $k$, random effects, $A_{j}^{(\mathrm{k})}$, may be correlated. Therefore, statistical comparisons are performed within subject by secretagogue type for a given intervention. Confidence intervals for basal secretion estimates were corroborated by bootstrap analysis (see the Methods section).

Variances and covariances of parameters are obtained explicitly from the inverse of the estimated information matrix:

$$
\Sigma^{(\mathrm{k})}=-\left(\frac{\partial^{2} \ell^{(\mathrm{k})}}{\partial \theta^{(\mathrm{k})} \partial \theta^{(\mathrm{k})^{\prime}}}\right)^{-1}
$$

evaluated at the maximum likelihood estimate, $\hat{\theta}^{(\mathrm{k})}$.

Thereby, statistical confidence intervals are calculated directly for basal secretion, $\hat{\gamma}^{(\mathrm{k})}$, and waveform parameters, $\hat{\beta}_{1}^{(\mathrm{k})}, \hat{\beta}_{2}^{(\mathrm{k})}$ and $\hat{\beta}_{3}^{(\mathrm{k})}$. The statistical mode (most commonly represented value) of the time delay to attain the maximal $\mathrm{GH}$-secretion rate within a burst is given as $h\left(\hat{\beta}_{1}^{(\mathrm{k})}, \hat{\beta}_{2}^{(\mathrm{k})}, \beta_{3}^{(\mathrm{k})}\right)=\hat{\beta}_{2}^{(\mathrm{k})}\left(\hat{\beta}_{1}^{(\mathrm{k})}-\left(1 / \hat{\beta}_{3}^{(\mathrm{k})}\right)\right)^{\left(1 / \hat{\beta}_{3}^{(\mathrm{k})}\right)}$. Variance of this value is computed by the multivariate delta method as:

$$
\sum_{i, j=1}^{3} \sigma_{i j}^{(k)} \frac{\partial h}{\partial \beta_{i}^{(k)}} \frac{\partial h}{\partial \beta_{j}^{(k)}}
$$

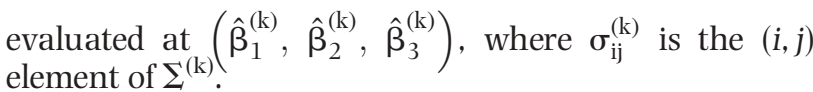

The principal deconvolution-derived analytical outcomes after both testosterone and placebo administration were (i) basal and pulsatile GH secretion during saline infusion $(\mu \mathrm{g} / \mathrm{l}$ per $5 \mathrm{~h}$ ), (ii) the mass of $\mathrm{GH}$ secreted in bursts after saline or secretagogue injection $(\mu \mathrm{g} / \mathrm{l}$ per $3 \mathrm{~h}$ ) and (iii) the modal time latency (min) to maximal GH secretion within secretory bursts. Analytical confidence intervals were corroborated by the bootstrap procedure (Monte Carlo shuffling of residuals and re-fitting of parameters).

\section{Other statistical comparisons}

To test the postulate that testosterone compared with placebo was stimulatory, a paired one-tailed Student's t-test was used to compare data within subjects. Bonferroni correction was applied whenever hypotheses and/or biological outcomes were not independent a priori (36). Linear regression analysis was applied to examine the relationship between GH secretory-burst mass and abdominal visceral fat mass (CT cross-sectional area) in the combined cohorts (37). Data are presented as the arithmetic mean \pm s.E.M. or median. $P<0.05$ was construed as significant, except for linear regressions when $P$ was Bonferroni-protected at 0.0167 .

\section{Results}

Table 1 summarizes mean fasting concentrations of testosterone, estradiol, SHBG, LH, FSH, GH and IGF-I measured after placebo and testosterone supplementation. Two-way ANOVA showed no order effect among the four testosterone sessions $(P=0.88)$. Concentrations of LH, FSH and SHBG declined, whereas those of testosterone, estradiol, GH and IGF-I rose, following testosterone administration. Figure 1 presents mean \pm S.E.M. GH concentration time series for each of the four infusions performed after placebo and testosterone administration in the cohort of seven men. Data reflect sampling every $10 \mathrm{~min}$ for $5 \mathrm{~h}$ in association with randomly ordered i.v. infusions of saline, L-arginine/GHRH, L-arginine/GHRP-2 and GHRH/GHRP-2 on separate study days. The stimulatory effect of testosterone in the saline session is evident.

Figure 2 summarizes deconvolution-based estimates of GH-secretion rates ( $\mu \mathrm{g} / \mathrm{l}$ per $5 \mathrm{~h}$ ) during saline infusion. Statistical comparisons revealed that testosterone compared with placebo administration augmented fasting basal GH secretion by 3 -fold $(P<0.005)$ and pulsatile GH secretion by 1.8 -fold $(P<0.01)$. Total GH secretion rose commensurately by 1.9-fold

Table 1 Baseline fasting hormone concentrations in healthy older men.

\begin{tabular}{lcc}
\hline & \multicolumn{2}{c}{ Baseline fasting concentration } \\
\cline { 2 - 3 } & Placebo & Testosterone \\
\hline $\mathrm{GH}(\mu \mathrm{g} / \mathrm{l})$ & $0.45 \pm 0.11$ & $0.87 \pm 0.24^{\star *}$ \\
$\mathrm{IGF}-\mathrm{I}(\mu \mathrm{g} / \mathrm{l})$ & $195 \pm 6.5$ & $233 \pm 9.2^{\star *}$ \\
$\mathrm{SHBG}(\mathrm{nM})$ & $48 \pm 6.1$ & $38 \pm 4.0^{*}$ \\
Testosterone $(\mathrm{nM})$ & $13 \pm 2.6$ & $36 \pm 5.7^{\star *}$ \\
Estradiol $(\mathrm{pM})$ & $88 \pm 10$ & $160 \pm 23^{\star *}$ \\
$\mathrm{LH}(\mathrm{IU} / \mathrm{l})$ & $4.5 \pm 1.6$ & $0.48 \pm 0.28^{* *}$ \\
FSH $(\mathrm{IU} / \mathrm{l})$ & $5.5 \pm 2.0$ & $0.68 \pm 0.24^{\star *}$ \\
\hline
\end{tabular}

Data are means \pm S.E.M. ( $n=7$ subjects).

${ }^{\star} P<0.05 ;{ }^{\star \star} P<0.01$ compared with the placebo effect. 


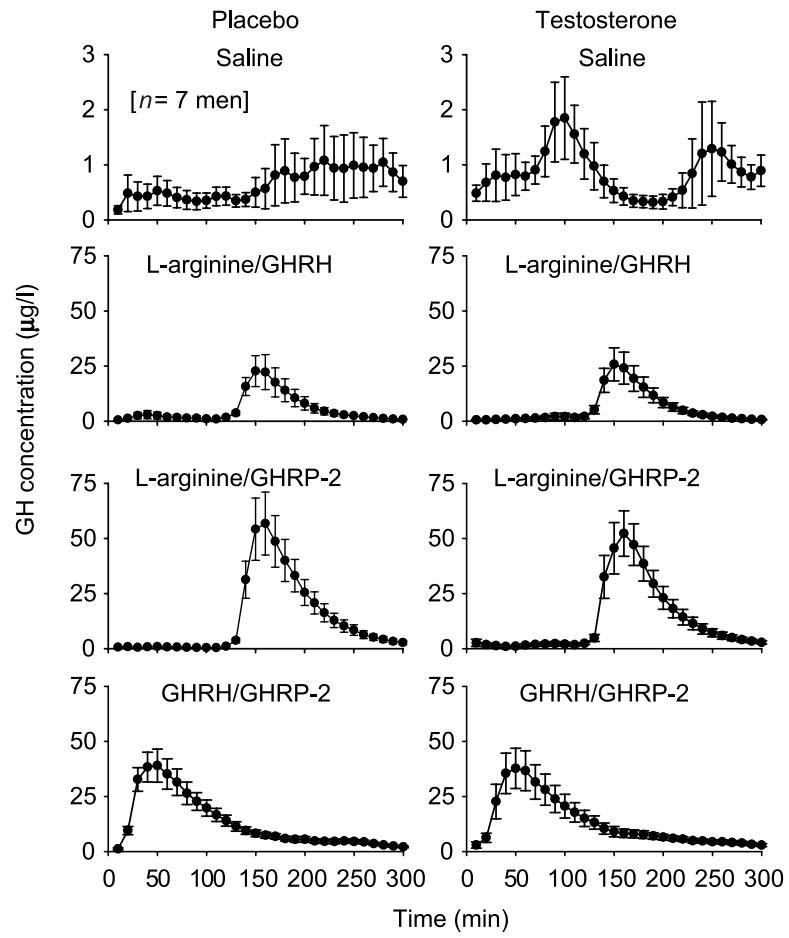

Figure 1 Mean \pm S.E.M. GH concentration time series in seven older men sampled every $10 \mathrm{~min}$ for $5 \mathrm{~h}$ fasting in a total of eight separate sessions after short-term supplementation with testosterone or placebo. Saline or the indicated secretagogue pairs were infused to induce GH secretion. L-Arginine was delivered over $30 \mathrm{~min}$ immediately prior to bolus i.v. injection of a maximally effective dose of GHRH $(1 \mu \mathrm{g} / \mathrm{kg})$ or GHRP-2 $(3 \mu \mathrm{g} / \mathrm{kg})$. GHRH and GHRP-2 (GHRH/GHRP-2) were infused together continuously i.v. for $3 \mathrm{~h}(1 \mu \mathrm{g} / \mathrm{kg} / \mathrm{h}$ each) in the absence of $\mathrm{L}$-arginine exposure.

$(P<0.01)$. In constrast, the mean GH interpulse interval (reciprocal of pulse frequency) did not change: $71 \pm 7.5 \mathrm{~min}$ for placebo and $88 \pm 14 \mathrm{~min}$ for testosterone.

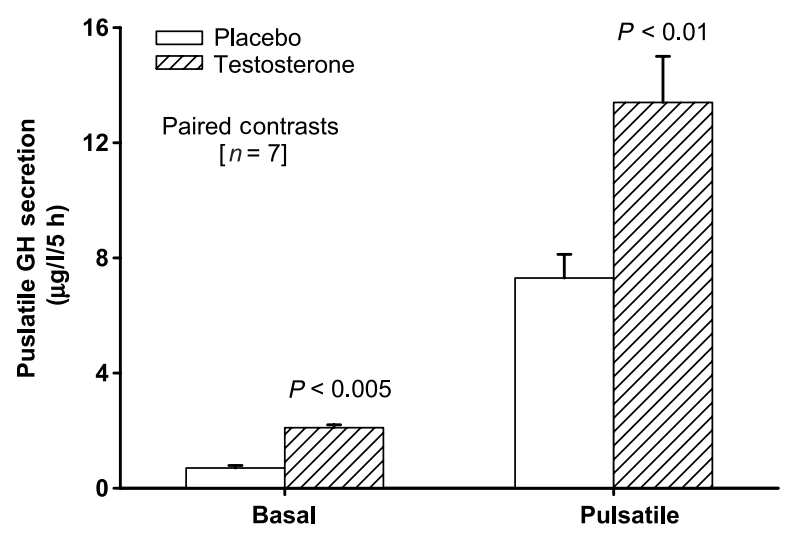

Figure 2 Impact of testosterone versus placebo administration on fasting basal and pulsatile GH secretion ( $\mu \mathrm{g} / \mathrm{l}$ per $5 \mathrm{~h}$ ) during saline infusion. $P$ values denote contrasts between testosterone and placebo. Data are means \pm S.E.M. ( $n=7$ subjects).
Figure 3 shows the effects of saline and each specific secretagogue pair on pulsatile GH secretion, defined as the summed mass of $\mathrm{GH}$ secreted in bursts $(\mu \mathrm{g} / \mathrm{l}$ per $3 \mathrm{~h}$ ). If expressed for ease of discussion as fractional (fold) stimulation over saline, responses were as follows: L-arginine/GHRH, 7.5 \pm 2.5 and 7.6 \pm 2.3 -fold (not significant for placebo versus testosterone, $P<0.05$ versus saline); L-arginine/GHRP-2, $23 \pm 6.0$ and $26 \pm 5.8$-fold (not significant for placebo versus testosterone, $\quad P<0.01$ versus saline); and combined GHRH/GHRP-2, 20 \pm 3.8 and 22 \pm 4.7 -fold (not significant for placebo versus testosterone, $P<0.01$ versus saline). Statistical contrasts among secretagogue combinations disclosed the following descending rank order of stimulus efficacy: L-arginine/GHRP-2 $=$ GHRH/GHRP-2 > L-arginine/GHRH > saline for both the placebo and testosterone interventions.

Figure 4 portrays analytically reconstructed GH secretory-burst shapes (time course of hormone release within a secretory event). Secretory-burst shape is independent of the amount of $\mathrm{GH}$ secreted within a pulse (see Fig. 3 for mass estimates). During saline infusion, the median values for the set of modal time delays to peak GH secretion within bursts were 31 and $30 \mathrm{~min}$ for placebo and testosterone exposure, respectively (not significant). Each secretagogue pair reduced the time latency to maximal GH secretion within bursts by approximately 50\% compared with that of saline: range of median values, 16-19 min after placebo and $12-15 \mathrm{~min}$ after testosterone $(P<0.001$ versus saline for each; not significant for testosterone versus placebo). Table 2 gives mean \pm s.E.M. time delays in relation to each secretagogue combination, showing that there were no significant subgroup contrasts. Both the median and the mean estimates are presented (see footnotes in Table 2).

Linear regression analysis was used to examine whether CT-estimated abdominal visceral fat (AVF) predicts stimulated GH secretory-burst mass. At Bonferroni-protected $P=0.0167$ (for three comparisons), L-arginine-/GHRH-stimulated GH secretory-burst mass correlated negatively with AVF following testosterone supplementation $\left(R^{2}=0.54, P=0.015\right.$; Fig. 5$)$.

\section{Discussion}

The present investigation utilized a strategy of single and dual peptide stimulation to assess mechanisms of impaired pulsatile GH secretion in healthy older men. This approach permitted several novel insights. First, the rank order of efficacy of paired stimuli was L-arginine/GHRP-2 (23-fold over saline $)=$ GHRH/GHRP-2 (20-fold) > L-arginine/GHRH (7.5-fold). Accordingly, GHRP combined with a second secretagogue is an effective stimulus of $\mathrm{GH}$ secretion in the elderly male. The prominent actions of GHRP putatively reflect the tripartite capability of this class of secretagogues to 


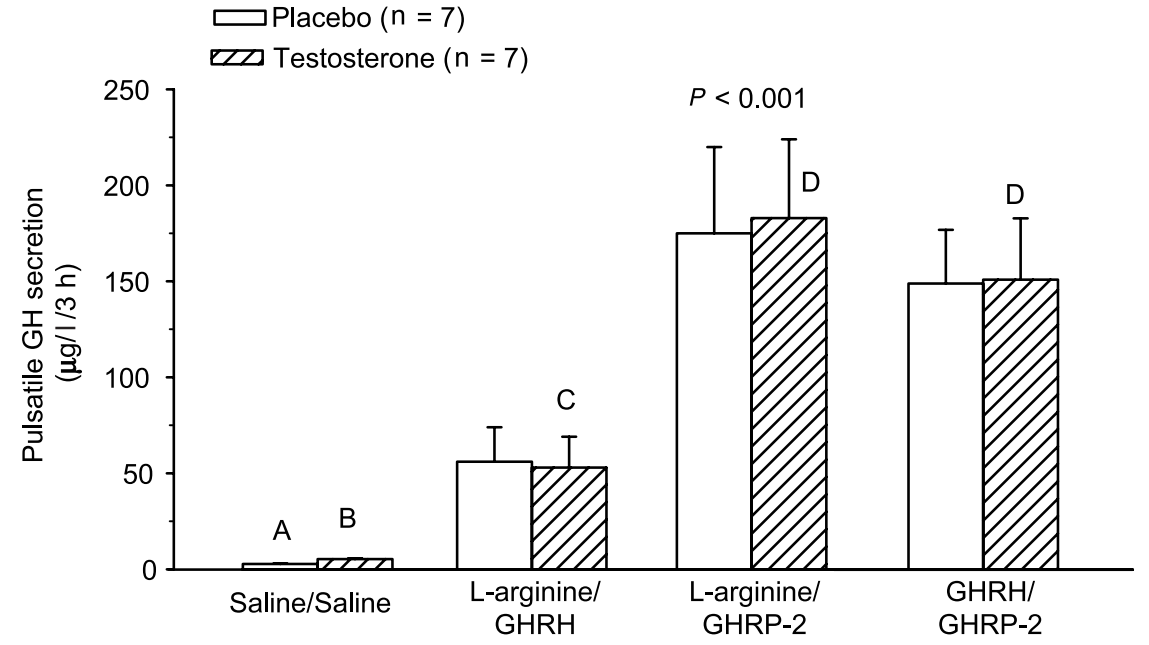

Figure 3 Summed GH secretory-burst mass ( $\mu \mathrm{g} / \mathrm{l}$ per $3 \mathrm{~h})$ estimated following paired secretagogue stimulation during supplementation with testosterone and placebo. Data are means \pm S.E.M. $(n=7$ men). oppose inhibitory effects of somatostatin on the central nervous system and pituitary gland, stimulate somatotrope GH secretion directly, and induce and synergize with hypothalamic GHRH release (38-41). Second, statistical comparisons performed on a within-subject basis disclosed that a schedule of testosterone supplementation that nearly doubles GH secretion and elevates IGF-I concentrations in aging men does not significantly alter hypothalamo-pituitary responsiveness to selectively paired secretagogues. And third, regression analysis revealed that CT-estimated AVF is a significantly negative predictor of L-arginine/GHRHstimulated $\mathrm{GH}$ secretory-burst mass accounting for
$54 \%$ of interindividual response variability. These outcomes provide strong evidence for multifactorial mediation of testosterone-driven $\mathrm{GH}$ production, rather than absolute upregulation of the GHRH and/or GHRP effector pathways in healthy older men, quite unlike the mechanisms proposed in androgendeficient boys (see the Introduction).

Available studies indicate that minute-to-minute variations in hypothalamic somatostatin secretion may confound facile interpretation of acute $\mathrm{GH}$ responses to secretagogues $(13,42)$. For this reason, we infused L-arginine just before administering a maximally stimulatory dose of GHRH or GHRP-2. L-Arginine putatively

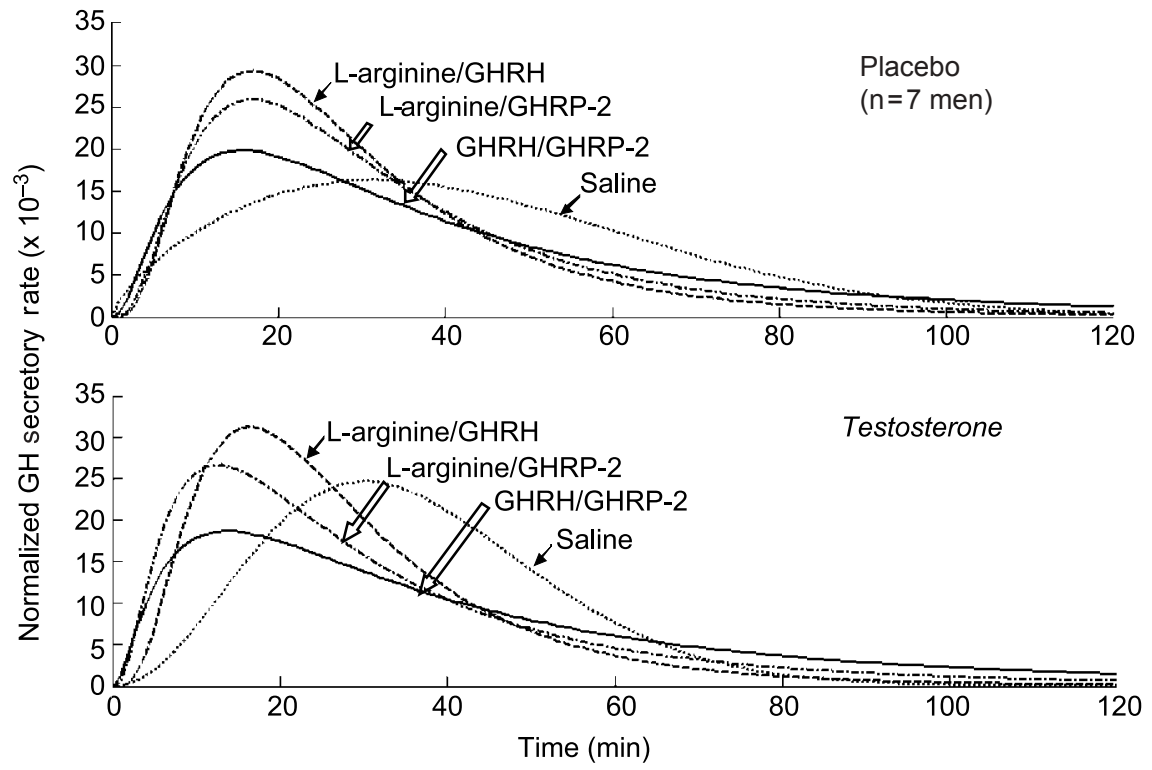

Figure 4 Analytically reconstructed GH secretory-burst shape (waveform) after administration of placebo and testosterone (top and bottom panels, respectively) followed by i.v. infusion of saline, L-arginine/GHRH, L-arginine/GHRP-2 and GHRH/GHRP-2. The normalized waveform is the probabilistic (unit-area normalized) time course of GH secretion within a discrete burst (see the Methods section). The endpoint is the modal time delay to achieve maximal GH release (see Table 2). The waveform is parameterized independently of the mass of GH released within the burst (Fig. 3). 
Table 2 Modal time delays within GH secretory bursts to attain maximal secretion.

\begin{tabular}{|c|c|c|c|c|}
\hline & $\begin{array}{c}\text { Secretagogue } \\
\text { type Saline }\end{array}$ & $\begin{array}{l}\text { L-Arginine/ } \\
\text { GHRP-2 }\end{array}$ & $\begin{array}{l}\text { L-Arginine/ } \\
\text { GHRH }\end{array}$ & $\begin{array}{c}\text { GHRP-2/ } \\
\text { GHRH }\end{array}$ \\
\hline \multicolumn{5}{|l|}{ Analytical* } \\
\hline Placebo & $31 \pm 6.8 \dagger$ & $19 \pm 3.4$ & $16 \pm 6.3$ & $18 \pm 2.4$ \\
\hline Testosterone & $30 \pm 13 t$ & $15 \pm 3.1$ & $15 \pm 5.4$ & $12 \pm 3.2$ \\
\hline \multicolumn{5}{|l|}{ Empirical** } \\
\hline Placebo & $34 \pm 4.6 \dagger$ & $20 \pm 3.4$ & $20 \pm 3.8$ & $20 \pm 2.4$ \\
\hline Testosterone & $40 \pm 12 \dagger$ & $17 \pm 3.2$ & $19 \pm 3.9$ & $14 \pm 2.3$ \\
\hline
\end{tabular}

* Median ( \pm S.E.M.) of analytical estimate (see appendix).

** Bootstrap mean ( \pm S.E.M.) (Monte Carlo shuffling of random residuals followed by re-estimation of parameters.

$\dagger P<0.01$ versus each secretagogue.

restricts central nervous system release of somatostatin, thereby allowing relatively unopposed stimulation by the infused secretagogue (see the Methods section). In the low-somatostatin milieu, exposure to a high concentration of testosterone did not amplify the maximal stimulatory effect of either secretagogue. Based upon estimates of statistical power (see the Results section), the foregoing outcomes argue against clinically significant testosterone-dependent facilitation of the efficacy of either GHRH or GHRP in healthy older men. The paradigm of testosterone supplementation concomitantly increased estradiol concentrations by about 2.5-fold. This point is significant, because estradiol supplemen-

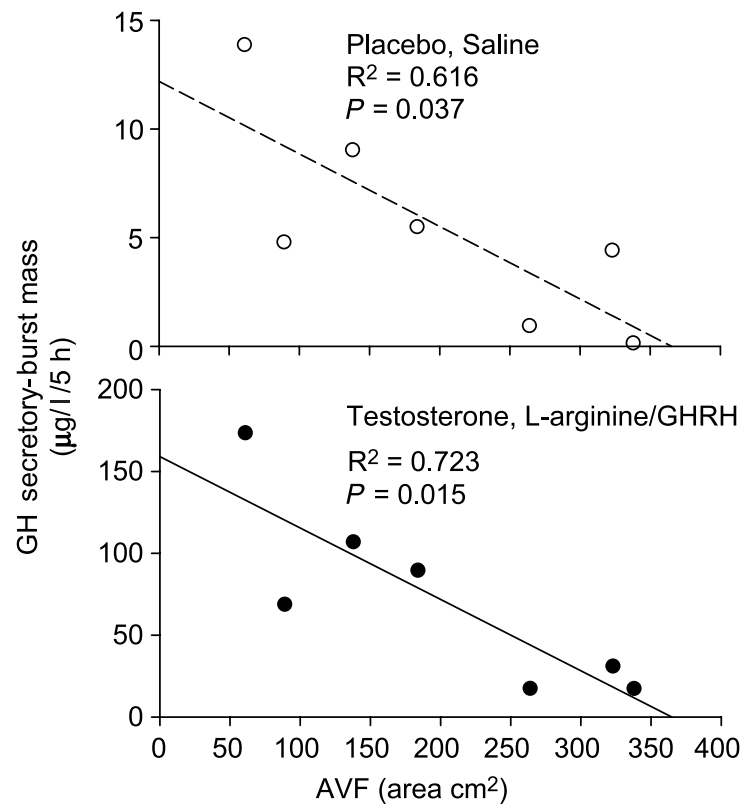

Figure 5 Linear regression of L-arginine-/GHRH-stimulated GH secretory-burst mass ( $y$ axis, $\mu \mathrm{g} / \mathrm{l}$ per $3 \mathrm{~h}$ ) on estimated AVF ( $x$ axis, CT scan cross-sectional area, $\mathrm{cm}^{2}$ ) after testosterone administration in older men. The square of the correlation coefficient $\left(R^{2}\right)$ provides an estimate of the fraction of the total variation in $\mathrm{GH}$ secretory-burst mass that is explained by differences in AVF. tation in postmenopausal women nearly doubles maximal stimulation by GHRP-2, albeit not by recombinant human GHRH-1,44-amide $(21,22,28)$. The difference in older men and women could indicate that a product of testosterone metabolism serves to inhibit and/or that higher estradiol concentrations are required to potentiate GHRP drive.

Infusion of any of the three pairs of secretagogues elicited twofold more-rapid initial $\mathrm{GH}$ release within secretory bursts compared with the response to saline (Fig. 4). This novel inference was possible using a new flexible-waveform model of deconvolution analysis, which allows estimation of skewed secretory-burst shapes (26-28). The methodology has been verified statistically and validated experimentally in human, sheep and horse $(33,43-45)$. From a biological perspective, accelerated initial GH release probably reflects more rapid exocytosis of $\mathrm{GH}$ from somatotrope secretory granules (13). Testosterone supplementation did not influence the prominent effect of secretagogues on GH secretory-burst shape. On the other hand, estradiol compared with placebo administration in postmenopausal women accelerated GHRH-stimulated GH release twofold (28). The basis for these response differences is not clear.

Supplementation with testosterone did not augment the effect of combined stimulation with GHRH and GHRP-2 in healthy elderly men. According to modelbased predictions, the result would suggest that elevated testosterone concentrations do not significantly attenuate somatostatinergic inhibition (46-48). This interpretation in part reflects our finding that testosterone also does not modify maximal individual stimulation by GHRH or GHRP-2 following L-arginine infusion, and the assumption that combined GHRH and GHRP-2 stimulation does not exhaust releasable $\mathrm{GH}$ stores. The last inference is supported by the fact that simultaneous infusion of L-arginine, GHRH and GHRP is required to evoke maximal GH release in both young and older adults (49).

Linear regression analysis disclosed that CT-estimated AVF was a significantly negative predictor of L-arginine/ GHRH-stimulated GH secretion in testosterone-supplemented men, accounting for more than $50 \%$ of the response variability. A similar inference was made for pulsatile GHRH-induced GH secretion in another analysis in aging men, which omitted L-arginine and included obese subjects (4). To the degree that L-arginine antagonizes hypothalamic somatostatin release, we infer that the negative relationship between combined L-arginine/ GHRH-stimulated GH secretion and AVF is not attributable solely to heightened somatostatin outflow. Plausible mechanisms would include impaired stimulation by GHRH acting alone or in synergy with endogenous ghrelin, given the strong facilitative interaction between these two peptides (50).

Qualifications in the present study are, first, that maximally stimulatory doses of GHRH and GHRP-2 
specifically evaluate secretagogue efficacy. Thus our data would not exclude possible testosterone-induced changes in secretagogue sensitivity or potency. Second, the apparent role of testosterone in unmasking an inverse relationship between $\mathrm{GH}$ responses to L-arginine/GHRH and AVF should be corroborated, given the relatively small cohort evaluated. Third, the testosterone-supplementation schedule chosen was shown to double GH secretion and elevate IGF-I concentrations in older men, as confirmed here, but yields peak testosterone and estradiol concentrations that exceed the normal range in some subjects (51). The precise dose-response relationship of the effects of testosterone on GH and IGF-I production in older men is not known.

In summary, the rank order of single and dual peptide efficacy unmasked here demonstrates prominent actions of GHRP in older men in both unmodified and high-testosterone milieux. Compared with saline, each of the three secretagogue pairs accelerated initial GH release within the induced secretory bursts, consistent with rapid exocytosis of somatotrope granules. The response to combined L-arginine/GHRH drive in the high-testosterone setting correlated negatively with AVF, accounting for greater than $50 \%$ of interindividual response variability. Based upon these findings, we postulate that interactive mechanisms not requiring increased GHRH or GHRP efficacy mediate testosterone-dependent stimulation of GH production in older men.

\section{Acknowledgements}

We thank Kris Nunez for excellent support of manuscript preparation, the Mayo Immunochemical Laboratory for assay assistance and the Mayo research nursing staff for conducting the protocol. Support was provided by grants K01 AG19164 and R01 AG19695 from the National Institutes of Health (Bethesda, MD, USA), DMS-0107680 Interdisciplinary Grant in the Mathematical Sciences from the National Sciences Foundation (Washington DC, USA) and M01 RR00585 to the General Clinical Research Center of the Mayo Clinic and Foundation from the National Center for Research Resources (Rockville, MD, USA).

\section{References}

1 Finkelstein JW, Roffwarg HP, Boyar RM, Kream J \& Hellman L. Age-related change in the twenty-four-hour spontaneous secretion of growth hormone. Journal of Clinical Endocrinology Metabolism 197235 665-670.

2 Ho KKY, Evans WS, Blizzard RM, Veldhuis JD, Merriam GR, Samojlik E, Furlanelto R, Rogol AD, Kaiser DL \& Thorner MO. Effects of sex and age on the 24-hour profile of growth hormone secretion in man: importance of endogenous estradiol concentrations. Journal of Clinical Endocrinology Metabolism $1987 \mathbf{6 4}$ $51-58$.

3 Mauras N, Blizzard RM, Link K, Johnson ML, Rogol AD \& Veldhuis JD. Augmentation of growth hormone secretion during puberty: evidence for a pulse amplitude-modulated phenomenon. Journal of Clinical Endocrinology Metabolism 198764 596-601.

4 Iranmanesh A, South S, Liem AY, Clemmons D, Thorner MO, Weltman A \& Veldhuis JD. Unequal impact of age, percentage body fat, and serum testosterone concentrations on the somatotrophic, IGF-I, and IGF-binding protein responses to a three-day intravenous growth hormone-releasing hormone pulsatile infusion in men. Euopean Journal of Endocrinology 1998139 59-71.

5 Gentili A, Mulligan T, Godschalk M, Clore J, Patrie J, Iranmanesh A \& Veldhuis JD. Unequal impact of short-term testosterone repletion on the somatotropic axis of young and older men. Journal of Clinical Endocrinology Metabolism 200287 825-834.

6 Keenan BS, Richards GE, Ponder SW, Dallas JS, Nagamani M \& Smith ER. Androgen-stimulated pubertal growth: the effects of testosterone and dihydrotestosterone on growth hormone and insulin-like growth factor-I in the treatment of short stature and delayed puberty. Journal of Clinical Endocrinology Metabolism $199376996-1001$.

7 Veldhuis JD, Metzger DL, Martha PM Jr, Mauras N, Kerrigan JR, Keenan B, Rogol AD \& Pincus SM. Estrogen and testosterone, but not a non-aromatizable androgen, direct network integration of the hypothalamo-somatotrope (growth hormone)-insulin-like growth factor I axis in the human: evidence from pubertal pathophysiology and sex-steroid hormone replacement. Journal of Clinical Endocrinology Metabolism 199782 3414-3420.

8 Giustina A, Scalvini T, Tassi C, Desenzani P, Poiesi C, Wehrenberg WB, Rogol AD \& Veldhuis JD. Maturation of the regulation of growth hormone secretion in young males with hypogonadotropic hypogonadism pharmacologically exposed to progressive increments in serum testosterone. Journal of Clinical Endocrinology Metabolism 199782 1210-1219.

9 Weissberger AJ \& Ho KKY. Activation of the somatotropic axis by testosterone in adult males: evidence for the role of aromatization. Journal of Clinical Endocrinology Metabolism 199396 1407-1412.

10 Devesa J, Lois N, Arce V, Diaz MJ, Lima L \& Tresguerres JA. The role of sexual steroids in the modulation of growth hormone (GH) secretion in humans. Journal of Steroid Biochemistry and Molecular Biology 199140 165-173.

11 van Kesteren P, Lips P, Deville W, Popp-Snijders C, Asscheman H, Megens J \& Gooren L. The effect of one-year cross-sex hormonal treatment on bone metabolism and serum insulin-like growth factor-1 in transsexuals. Journal of Clinical Endocrinology Metabolism $1996812227-2232$.

12 Fryburg DA, Weltman A, Jahn LA, Weltman JY, Samolijik E \& Veldhuis JD. Short-term modulation of the androgen milieu alters pulsatile but not exercise or GHRH-stimulated GH secretion in healthy men. Journal of Clinical Endocrinology Metabolism 1997 $823710-3719$.

13 Giustina A \& Veldhuis JD. Pathophysiology of the neuroregulation of growth hormone secretion in experimental animals and the human. Endocrine Reviews 199819 717-797.

14 Godfrey P, Rahal JO, Beamer WG, Copeland NG, Jenkins NA \& Mayo KE. GHRH receptor of little mice contains a missense mutation in the extracellular domain that disrupts receptor function. Nature Genetics 19934 227-232.

15 Shuto Y, Shibasaki T, Otagiri A, Kuriyama H, Ohata H, Tamura H, Kamegai J, Sugihara H, Oikawa S \& Wakabayashi I. Hypothalamic growth hormone secretagogue receptor regulates growth hormone secretion, feeding, and adiposity. Journal of Clinical Investigation $20021091429-1436$.

16 Bowers CY. New insight into the control of growth hormone secretion. In Central and Peripheral Mechanisms in Pituitary Disease, pp 163-175. Eds DL Kleinberg \& DR Clemmons. Bristol: BioScientifica, 2002.

17 Low MJ, Otero-Corchon V, Parlow AF, Ramirez JL, Kumar U, Patel YC \& Rubinstein M. Somatostatin is required for masculinization of growth hormone-regulated hepatic gene expression but not of somatic growth. Journal of Clinical Investigation 2001107 1571-1580. 
18 Loche S, Colao A, Cappa M, Bellone J, Aimaretti G, Farello G, Faedda A, Lombardi G, Deghenghi R \& Ghigo E. The growth hormone response to hexarelin in children: reproducibility and effect of sex steroids. Journal of Clinical Endocrinology Metabolism 1997 $82861-864$.

19 Penalva A, Pombo M, Carballo A, Barreiro J, Casanueva FF \& Dieguez C. Influence of sex, age, and adrenergic pathways on the growth hormone response to GHRP-6. Clinical Endocrinology 199338 87-91.

20 Arvat E, Broglio F, Giordano R, Muccioli G, Maccario M, Camanni F \& Ghigo E. Hormonal activities of growth hormone secretagogues (GHS) across lifespan. In Growth Hormone Secretagogues, pp 139-155. Eds M Ghigo, M Boghen, FF Casanueva \& C Dieguez. New York: Elsevier Science, 1999.

21 Anderson SM, Shah N, Evans WS, Patrie JT, Bowers CY \& Veldhuis JD. Short-term estradiol supplementation augments growth hormone $(\mathrm{GH})$ secretory responsiveness to dose-varying GH-releasing peptide infusions in healthy postmenopausal women. Journal of Clinical Endocrinology Metabolism $2001 \mathbf{8 6}$ $551-560$.

22 Veldhuis JD, Evans WS \& Bowers CY. Estradiol supplementation enhances submaximal feedforward drive of growth hormone (GH) secretion by recombinant human GH-releasing hormone1,44-amide in a putatively somatostatin-withdrawn milieu. Journal of Clinical Endocrinology Metabolism $2003 \mathbf{8 8} 5484-5489$.

23 Bermann M, Jaffe CA, Tsai W, DeMott-Friberg R \& Barkan AL. Negative feedback regulation of pulsatile growth hormone secretion by insulin-like growth factor I: involvement of hypothalamic somatostatin. Journal of Clinical Investigations 199494 $138-145$.

24 Ghigo E, Bellone J, Mazza E, Imperiale E, Procopio M \& Valente F. Arginine potentiates the GHRH- but not the pyridostigmineinduced GH secretion in normal short children. Further evidence for a somatostatin-suppressing effect of arginine. Clinical Endocrinology (Oxford) 1990 32 763-777.

25 Gianotti L, Maccario M, Lanfranco F, Ramunni J, Di Vito L, Grottoli S, Mueller EE, Ghigo E \& Arvat E. Arginine counteracts the inhibitory effect of recombinant human insulin-like growth factor I on the somatotroph responsiveness to growth hormonereleasing hormone in humans. Journal of Clinical Endocrinology Metabolism 200085 3604-3608.

26 Keenan DM, Veldhuis JD \& Yang R. Joint recovery of pulsatile and basal hormone secretion by stochastic nonlinear random-effects analysis. American Journal of Physiology Regulatory, Integrative $\mathcal{E}$ Comparative Physiology 1998275 R1939-R1949.

27 Keenan DM, Roelfsema F, Biermasz N \& Veldhuis JD. Physiological control of pituitary hormone secretory-burst mass, frequency and waveform: a statistical formulation and analysis. American Journal of Physiology Regulatory, Integrative \& Comparative Physiology 2003285 R664-R673.

28 Veldhuis JD, Anderson SM, Kok P, Iranmanesh A, Frystyk J, Orskov H \& Keenan DM. Estradiol supplementation modulates growth hormone $(\mathrm{GH})$ secretory-burst waveform and recombinant human insulin-like growth factor-I-enforced suppression of endogenously driven GH release in postmenopausal women. Journal of Clinical Endocrinology Metabolism $2004891312-1318$.

29 Shah N, Evans WS \& Veldhuis JD. Actions of estrogen on the pulsatile, nyctohemeral, and entropic modes of growth hormone secretion. American Journal of Physiology Regulatory, Integrative $\mathcal{E}$ Comparative Physiology 1999276 R1351-R1358.

30 Anderson SM, Wideman L, Patrie JT, Weltman A, Bowers CY \& Veldhuis JD. Estradiol supplementation selectively relieves GH's autonegative feedback on GH-releasing peptide-2-stimulated $\mathrm{GH}$ secretion. Journal of Clinical Endocrinology Metabolism 200186 5904-5911.

31 Vahl N, Jorgensen JO, Skjaerback C, Veldhuis JD, Orskov H \& Christiansen J. Abdominal adiposity rather than age and sex predicts the mass and patterned regularity of growth hormone secretion in mid-life healthy adults. American Journal of Physiology Endocrinology and Metabolism 1997272 E1108-E1116.
32 Veldhuis JD, Evans WS \& Johnson ML. Complicating effects of highly correlated model variables on nonlinear least-squares estimates of unique parameter values and their statistical confidence intervals: estimating basal secretion and neurohormone half-life by deconvolution analysis. Methods in Neuroscience $1995 \mathbf{2 8}$ $130-138$.

33 Keenan DM, Licinio J \& Veldhuis JD. A feedback-controlled ensemble model of the stress-responsive hypothalamo-pituitary-adrenal axis. PNAS 200198 4028-4033.

34 Soares-Welch C, Farhy LS, Mielke K, Mahmud F, Miles JM, Bowers CY \& Veldhuis JD. Complementary secretagogue pairs unmask prominent gender-related contrasts in mechanisms of growth-hormone pulse renewal in young adults. Journal of Clinical Endocrinology Metabolism 200590 2225-2232.

35 Veldhuis JD, Evans WS, Iranmanesh A, Weltman AL \& Bowers CY. Short-term testosterone supplementation relieves growth hormone autonegative feedback in men. Journal of Clinical Endocrinology Metabolism 200489 1285-1290.

36 Kuehl RO. Split-plot designs. In Statistical Principles of Research Design and Analysis, pp 473-498. Belmont, CA: Duxbury Press, 1994.

37 Fisher LD \& van Belle G. Descriptive statistics. In Biostatistics: A Methodology for the Health Sciences, pp 58-74. New York: John Wiley \& Sons, 1996.

38 Bowers CY, Momany FA, Reynolds A \& Hong A. On the in vitro and in vivo activity of a new synthetic hexapeptide that acts on the pituitary to specifically release growth hormone. Endocrinology $19841141537-1545$.

39 Fairhall KM, Mynett A \& Robinson ICAF. Central effects of growth hormone-releasing hexapeptide (GHRP-6) on growth hormone release are inhibited by central somatostatin action. Journal of Endocrinology $1995 \mathbf{1 4 4} 555-560$.

40 Fletcher TP, Thomas GB \& Clarke IJ. Growth hormone-releasing and somatostatin concentrations in the hypophysial portal blood of conscious sheep during the infusion of growth hormone-releasing peptide-6. Domestic Animals Endocrinology 1996 $13251-258$.

41 Magnan E, Cataldi M, Guillaume V, Conte-Devolx B, Graziani N, Figaroli JC, Thomas F, Chihara K \& Oliver C. Acute changes in growth hormone-releasing hormone secretion after injection of BIM 23014, a long acting somatostatin analog, in rams. Life Science $199251831-838$.

42 Muller EE, Locatelli V \& Cocchi D. Neuroendocrine control of growth hormone secretion. Physiological Reviews $1999 \mathbf{7 9}$ 511-607.

43 Keenan DM, Sun W \& Veldhuis JD. A stochastic biomathematical model of the male reproductive hormone system. SIAM Journal of Applied Mathematics $200061934-965$.

44 Keenan DM \& Veldhuis JD. Divergent gonadotropin-gonadal doseresponsive coupling in healthy young and aging men. American Journal of Physiology Regulatory, Integrative $\mathcal{E}$ Comparative Physiology 2004286 R381-R389.

45 Keenan DM, Alexander SL, Irvine CHG, Clarke IJ, Canny BJ, Scott CJ, Turner A, Tilbrook AJ \& Veldhuis JD. Reconstruction of in vivo time-evolving neuroendocrine dose-response properties unveils admixed deterministic and stochastic elements in interglandular signaling. PNAS 2004101 6740-6745.

46 Farhy LS, Straume M, Johnson ML, Kovatchev BP \& Veldhuis JD. A construct of interactive feedback control of the $\mathrm{GH}$ axis in the male. American Journal of Physiology Regulatory, Integrative \& Comparative Physiology 2001281 R38-R51.

47 Farhy LS \& Veldhuis JD. Joint pituitary-hypothalamic and intrahypothalamic autofeedback construct of pulsatile growth hormone secretion. American Journal of Physiology Regulatory, Integrative \& Comparative Physiology 2003285 R1240-R1249.

48 Farhy LS \& Veldhuis JD. Putative GH pulse renewal: periventricular somatostatinergic control of an arcuate-nuclear somatostatin and GH-releasing hormone oscillator. American Journal of Physiology Regulatory, Integrative \& Comparative Physiology 2004286 R1030-R1042. 
49 Arvat E, Ceda GP, Di Vito L, Ramunni J, Gianotti L \& Ghigo E. Agerelated variations in the neuroendocrine control, more than impaired receptor sensitivity, cause the reduction in the $\mathrm{GH}$ releasing activity of GHRP's in human aging. Pituitary 19981 $51-58$.

50 Tannenbaum GS, Epelbaum J \& Bowers CY. Interrelationship between the novel peptide ghrelin, somatostatin and growth hormone-releasing hormone in regulation of pulsatile growth hormone secretion. Endocrinology 2003144 967-974.

51 Waters DL, Qualls CR, Dorin R, Veldhuis JD \& Baumgartner RN. Increased pulsatility, process irregularity, and nocturnal trough concentrations of growth hormone in amenorrheic compared to eumenorrheic athletes. Journal of Clinical Endocrinology Metabolism 200086 1013-1019.

52 Faria ACS, Veldhuis JD, Thorner MO \& Vance ML. Half-time of endogenous growth hormone $(\mathrm{GH})$ disappearance in normal man after stimulation of GH secretion by GH-releasing hormone and suppression with somatostatin. Journal of Clinical Endocrinology Metabolism 198968 535-541.

Received 14 April 2005

Accepted 5 July 2005 